\title{
Variable Manifestations of Severe Hypoprothrombinemia (Factor II Deficiency): 2 Cases
}

Sirisha Rani S*, Darshak Makadia, Lokesh Lingappa, Nikit Shah and Ramesh Konanki

Department of Hematology Oncology, Department of Paediatric Neurology, Rainbow Children's Hospital and Perinatal Centre, Hyderabad, India

\begin{abstract}
Case 1 is a 28 months female child, who has been symptomatic from 8 month of age with multiple, painful bruises over legs once in 5 to 6 weeks. Her complete blood picture was normal.PT and APTT were prolonged with normal fibrinogen and liver function.

Case 2, became symptomatic from day 2 of life. He was treated for blood stained vomiting and black coloured stool and severe anaemia. Second episode was subdural hemorrhage and seizures. Investigations revealed abnormal PT and APTT with normal fibrinogen and liver function. Hereditary prothrombin deficiency is one of the rare congenital coagulation defect encountered in clinical practice. High index of suspicion is required to diagnose this condition with systematic approach as the facility to check factor 2 levels are not freely available in many centres. Bleeding manifestations are dependent on factor level. Children with severe deficiency are prone for life threatening bleeds. We report couple of children who had severe form of hereditary prothrombin deficiency with variable clinical manifestations. In both the cases, coagulation profile was suggestive of common pathway defect, PT and APTT were prolonged. Fibrinogen and Liver function tests were normal. No evidence of sepsis, no response to vitamin $\mathrm{K}$. Further evaluation revealed low prothrombin activity $(<1 \%)$. Factor $\mathrm{v}$ and $\mathrm{x}$ were normal.
\end{abstract}

Keywords: Hypoprothrombinemia; Prothrombin; Thromboplastin; Hemorrhage

\section{Introduction}

Prothrombin (factor 2) is a precursor to thrombin, which converts fibrinogen into fibrin, which in turn strengthens protective clot [1]. Deficiency of this factor results in impaired clotting mechanism and manifests as prolonged bleeding. There are two types of prothrombin deficiencies, hereditary and acquired. Hereditary prothrombin deficiency is an autosomal recessive inheritance rare congenital coagulation disorder with a prevalence of approximately 1:2,000,000 in the general population and nearly 100 cases are reported worldwide [1,2].

Hereditary hypoprothrobinemia can be either Type I prothrombin deficiency (hypoprothrombinemia) or Type II prothrombin deficiency (dysprothrombinemia)

Severity of clinical features varies from easy bruisability to severe intracranial hemorrhage and hematoma. It depends on prothrombin activity, patients with prothrombin activity of 5-50\% usually bleed following trauma and surgery, while those with prothrombin activity of $2-5 \%$, bleeding is variable and those with activity $<1 \%$, present with significant bleeding tendency [1-3].

Diagnosis is suspected with a prolonged prothrombin time (PT) and an activated partial thromboplastin time (APTT); definite diagnosis is through specific factor assay.

Acquired form of hypoprothrombinemia could be secondary to vitamin $\mathrm{K}$ deficiency, liver disease or autoimmune disorders like SLE. Oral anticoagulant therapy also can create acquired form of hypoprothrombinemia status [4,5]. In Systemic Lupus Erythematosus (SLE) hypoprothrombinemia is secondary to inhibitors to prothrombin. Studies of family members, checking ANA titres and measurement of vitamin $\mathrm{K}$ dependent coagulation factors helps to distinguish acquired from inherited prothombin deficiency $[1,2]$.

Simple bruises and mild superficial bleeding do not generally require therapy. Infusion of fresh frozen plasma (FFP) is adequate in most cases of bleeding. Plasma exchange transfusion may be used to increase factor II levels before surgery. Prothrombin complex concentrates either for treatment or prophylaxis are also recommended [6,7].

\section{Case 1}

A 28 months old girl, symptomatic from 8-months of age, born to second degree consanguineous couple, second in birth order presented with complaints of painful bruises over lower limbs, disturbed sleep at nights with pain. Her elder sibling was a male child, who also suffered from similar problem, died at the age of two years with bleeding. Diagnosis was not established.

Investigation of our patient had done elsewhere revealed prolonged PT and APTT.

Patient's complete blood counts (platelets 2.7 lakhs) and peripheral blood smear were normal. Both PT and APTT were more than $2 \mathrm{mts}$, which was getting corrected with normal plasma in mixing studies. Other investigations such as fibrinogen, liver function test, septic markers and bleeding time did not reveal any abnormality. There was no response to vitamin K. ANA was normal. Prothrombin activity was less than $1 \%$. She was transfused with fresh frozen plasma as per the need. Patient is now 28 months and she is thriving well. For recurrent painful bruises disturbing night sleep with pain, she is requiring FFP every 5-6 weeks, which resolves her symptoms.

*Corresponding author: Sirisha Rani S, Department of Hematology Oncology, Department of Paediatric Neurology, Rainbow Children's Hospital and Perinatal Centre, Hyderabad, India, Tel: 09959985558; E-mail: lokisiri@gmail.com

Received December 06, 2013; Accepted December 27, 2013; Published December 31, 2013

Citation: Sirisha Rani S, Makadia D, Lingappa L, Shah N, Konanki R (2013) Variable Manifestations of Severe Hypoprothrombinemia (Factor II Deficiency) 2 Cases. J Blood Disorders Transf 5: 192. doi: 10.4172/2155-9864.1000192

Copyright: $\odot 2013$ Sirisha Rani S, et al. This is an open-access article distributed under the terms of the Creative Commons Attribution License, which permits unrestricted use, distribution, and reproduction in any medium, provided the original author and source are credited. 
Citation: Sirisha Rani S, Makadia D, Lingappa L, Shah N, Konanki R (2013) Variable Manifestations of Severe Hypoprothrombinemia (Factor II Deficiency): 2 Cases. J Blood Disorders Transf 5: 192. doi: 10.4172/2155-9864.1000192

Page 2 of 2

\section{Case 2}

A 12 days old baby boy second child of third degree consanguineous couple, admitted with complaint of blood stained vomiting and black coloured stool at local hospital. He received vitamin $\mathrm{K}$ and FFP transfusion for coagulopathy (PT and APTT were prolonged) in local hospital. He was not investigated further at that time. No history of similar complaints in the family. On day 40 of life he had persistent vomiting and tonic posturing of the body. His CT brain revealed subdural hemorrhage. He had low hb of $7 \mathrm{gm} \%$, platelets were 3.5 lakhs/cu mm, PT was 51seconds and APTT 87 seconds. His prothrombin activity was less than $1 \%$. Fibrinogen, septic markers and LFT were normal. He required ventilator support, packed red blood cell (PRBC) transfusion, vitamin $\mathrm{K}$ and fresh frozen plasma (FFP). He was discharged after 7 days. At 2 and half months of age, he developed left ankle swelling secondary to bleed. He received FFP transfusion. At 3 months of age he came with irritability and excessive crying. His repeat CT brain revealed sub dural, sub arachnoid and intra parenchymal bleed with cystic encephalomalasia changes (Figures 1 and 2). $\mathrm{He}$ received same treatment.

He is now 6 months old, parents were counselled regarding nature of the condition, probable need of frequent transfusion. Also explained about possible poor neurological outcome secondary to extensive CNS bleed.

In both the patients there was no icterus, lymphadenopathy and visceromegaly. Their anthropometry was normal. In both the cases, common pathway defect was suspected on the basis of prolonged PT and APTT. There was no response to vitamin K. No evidence of sepsis or liver disease. Clotting factors assay including fibrinogen, factor $\mathrm{V}$ and factor $\mathrm{X}$ were normal. ANA was negative. Both had prothrombin activity $<1 \%$. Both the parents had normal PT and APTT. Their prothrombin activity was not done (Table 1 ).

\section{Discussion}

Patients with inherited severe hypoprothrombinaemia present early in life, whereas a patient with milder form may present later at any age. Severe life-threatening haemorrhage, including intracranial haemorrhage [6], is found in neonates with severe prothrombin deficiency and prophylactic therapy is recommended for them. Severe prothrombin deficiency leads to spontaneous abortion and foetal demise in some cases. Complete prothrombin deficiency has not been

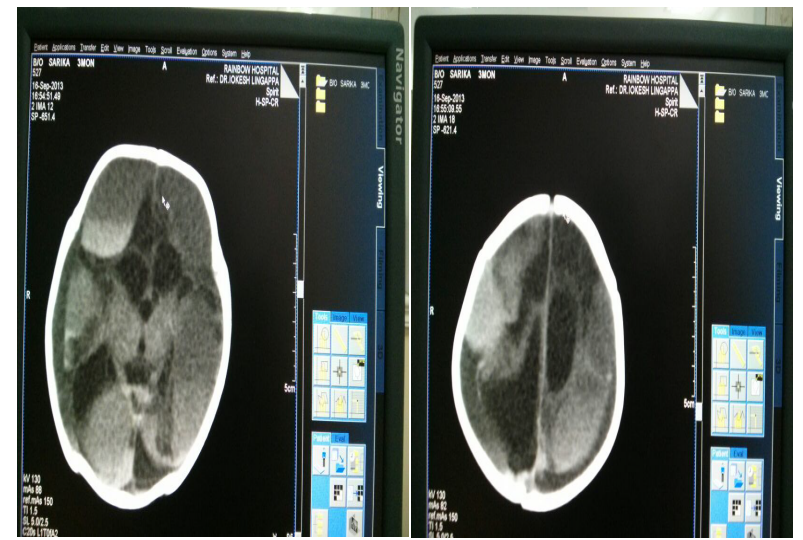

Figures 1 and 2: Bilateral subdural bleed, acute on chronic on right \& left parenchymal bleed with exvacua dilatation.

\begin{tabular}{|l|c|c|c|c|c|} 
& PT & APTT & $\begin{array}{c}\text { Fibrinogen } \\
\text { and LFT }\end{array}$ & ANA & $\begin{array}{c}\text { Factor 2 } \\
\text { activity }\end{array}$ \\
\hline Case 1 & $\begin{array}{c}\text { More than } \\
2 \mathrm{mts}\end{array}$ & More than $2 \mathrm{mts}$ & normal & normal & Less than $1 \%$ \\
\hline Case 2 & 51 & 87 & normal & normal & Less than 1\% \\
\hline
\end{tabular}

Table 1: As quantitative assement of factor 2 by immunological assay is not freely available, in our cases factor 2 activities has been done which was less than $1 \%$ in both the cases.

reported; suggesting that this condition is incompatible with life. In both acquired and inherited hypoprothrombinaemia, the morbidity and mortality risks are related to the circulating level of factor II [2]. Prophylactic treatment is suggested in children with severe deficiency (levels less than 2\%) with life threatening bleeds [6,7].

Despite having very low $(<1 \%)$ prothrombin level in both patients, case 1 girl had only subcutaneous bruises requiring FFP occasionally when symptomatic with painful bruises disturbing sleep. She is not on prophylactic treatment. Currently she is 28 months old and thriving well. Where as second child had recurrent intra cranial bleeds in early infancy and carries poor prognosis.

Moderate bleeding can be treated with Fresh Frozen Plasma Correction of prothrombin can also be achieved with the use of Prothrombin complex concentrates (PCCs) [3,8]. PCCs contain factors II, VII, IX and X. However, there are differences in the amount of factor II present in PCCs, depending upon the product. The major disadvantage of PCCs is a potential for thrombosis, presumably because of contamination of factors such as FXa and FIXa. The dose of infused product should not exceed 100 units $/ \mathrm{kg}$, and the frequency of infusion should be adjusted to maintain hemostasis but not excessive level of prothrombin.

\section{References}

1. Selighsohn U, White GC (2001) Inherited deficiency of coagulation factor. In Brutler E, Lichtman MA, Coller BS, Kipps TJ, Selighsohn U (Eds,). William Heamatology 6th (Edn,). McGraw Hill. pp 1617-1619.

2. Ejaz MS, Latif N, Memon A (2009) Hereditary prothrombin deficiency. J Pak Med Assoc 59: 637-639.

3. Freidmen KD, Ridgers GM (2004) Inherited coagulation disorders. In: Gree JP, Foerster J, Lukens JN, Rodgers GM Eds. Wintrobe's Clinical Heamatology (11th Edn)., Philadelphia:Lippencott William \& Wilkins; pp 1642-1643.

4. Jayandharan G, Vishwabandya A, Baidya S, Nair SC, Shaji RV, et al. (2005) Molecular genetics of hereditary prothrombin deficiencies in Indian patients: Identification of a novel A1a 362? Thr (Prothrombin Vellore 1) mutation. J Thromb Haemost 3: 1446-1453.

5. Mazodier K, Arnaud L, Mathian A, Costedoat-Chalumeau N, Haroche J, et al. (2012) Lupus anticoagulant-hypoprothrombinemia syndrome: report of 8 cases and review of the literature. Medicine (Baltimore), 91: 251-260.

6. Strijks E, Poort SR, Renier WO, Gabreëls FJ, Bertina RM (1999) Hereditary prothrombin deficiency presenting as intracranial haematoma in infancy. Neuropediatrics 30: 320-324.

7. Lobel JS, Majumdar S, Kovats-Bell S (2004) Successful prophylactic treatment for bleeding in a girl with severe hereditary prothrombin deficiency using a prothrombin complex concentrate. J Pediatr Hematol Oncol 26: 480-483.

8. Blanchette VS, Dean J, Lillicrap D (1999) Rare congenital hemorrhagic disorders. In: Lilleyman JS, Hann IM, Blanchette VS (Eds,). Pediatric Hematology (2ndedn,). Churchill Livingstone; pp 619-620.

Citation: Sirisha Rani S, Makadia D, Lingappa L, Shah N, Konanki R (2013) Variable Manifestations of Severe Hypoprothrombinemia (Factor II Deficiency): 2 Cases. J Blood Disorders Transf 5: 192. doi: 10.4172/21559864.1000192 